\title{
Defective Recognitive Immunity in Family Aggregates of Colon Carcinoma
}

\author{
Norman T. Berlinger, Carlos Lopez, Martin Lipkin, James E. Vogel, \\ and ROBERT A. GOOD
}

From the Memorial Sloan-Kettering Cancer Center, New York 10021

\begin{abstract}
A B S TRACT Cancer-free individuals from family aggregates of seemingly hereditary colon carcinoma were studied to determine the nature of their cellmediated immune capacities in mixed leukocyte culture. Members of families who demonstrated no evidence of a precancerous condition such as polyposis coli did demonstrate substantial cellular immunopathology. Of these, $44 \%$ showed a decreased responsiveness of their peripheral mononuclear cells to allogeneic stimuli, and in a number of these individuals this deficiency clearly manifested itself as an inappropriate suppression of potentially normal lymphocyte blastogenic capacities by an adherent population of mononuclear leukocytes. This in vitro defect of recognitive immunity appears to be the same type of defect that has already been described for individuals with established malignancies. The pattern of phenotypic expression of this immunopathology within these families is not inconsistent with an hereditary disorder. Individuals from families with a known hereditary somatic precancerous condition usually did not demontrate this immunopathology. It is appropriate to speculate that the defect of recognitive immunity in the former families could be contributory to the genesis of the colon carcinoma.
\end{abstract}

\section{INTRODUCTION}

Certain forms of cancer are doubtless hereditary. The basal cell nevus syndrome is a clear example of hereditary cutaneous cancer (1), and approximately $40 \%$ of all cases of retinoblastoma are hereditary (2). Genetic disorders which predispose to an inordinate risk of cancer include Down's syndrome (3), Fanconi's anemia (4), Bloom's syndrome (5), xeroderma pigmentosum (6), and certain immunodeficiency diseases (7).

Received for publication 4 June 1976 and in revised form 19 January 1977.
Adenocarcinoma of the colon is a most frequently occurring malignancy in the United States. Cancer of this site likewise has been shown to be related to hereditary precancerous conditions, namely familial colonic polyposis (8), Gardner's syndrome (9), and possibly Turcot's syndrome (10). Convincing evidence has recently accumulated, however, demonstrating that colon carcinoma can aggregate in families who show no evidence of a preexisting precancerous condition (11-15). These family aggregates demonstrate an increased frequency of many histological types of adenocarcinoma, an increased frequency of multiple malignancies of the same organ, an earlier age of onset of the malignancy as compared to the general population, and an apparent vertical mode of transmission.

The purpose of the present study was to characterize the phenotypic expression of the cell-mediated immune capacities of both affected and unaffected members of family aggregates of colon carcinoma because reports are extant documenting subclinical immune defects in healthy relatives of family aggregates of lymphoproliferative disorders (16-18) and of gastric cancer (19). We have focused attention both on lymphocyte responsiveness in mixed leukocyte culture $(M L C)^{1}$ and on the modulatory role of the adherent mononuclear cell in MLC because we have previously demonstrated that some patients with various established nonlymphoid malignancies can possess apparently perturbed adherent cells which attenuate the responsiveness of their lymphocytes in MLC (20). Such an analysis becomes especially cogent in light of the findings that adherent cells can secrete discrete factors which are inhibitory or stimulatory

\footnotetext{
${ }^{1}$ Abbreviations used in this paper: FH cells, mononuclear cells isolated by Ficoll-Hypaque flotation; G-10 cells, mononuclear cells isolated by Ficoll-Hypaque flotation and filtered through columns of Sephadex G-10 beads; MLC, mixed leukocyte culture; RR, relative response of FH cells; $R_{f}$, relative response of $G-10$ cells; $R V$, reference value.
} 
cooven concenom

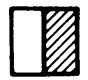

FAMILIAL POLYPOSIS

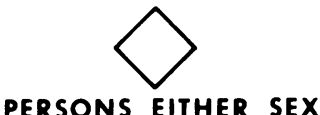

OTHER MALIGNANCY
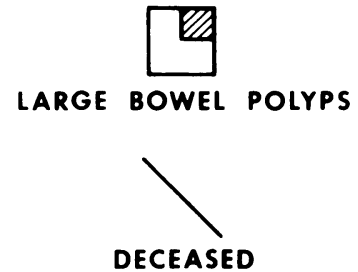

\section{CONSANGUINITY}

FIGURE 1 Key to symbols used in pedigrees.

for cell proliferation (21) or can exert nonspecific influences which are either cytostimulatory (22) or cytostatic (23).

\section{METHODS}

Patient selection. A total of 23 individuals from five family aggregates of colon carcinoma were studied. Of these, five patients had a current or previous adenocarcinoma of the colon. The remaining 18 individuals were unaffected blood relatives (mostly offspring) of the patients with cancer. Each of these families fulfilled at least two of the following criteria: $(a)$ adenocarcinoma of the colon appearing in three successive generations; (b) adenocarcinoma of the colon appearing with a higher than expected frequency in the family as a whole or in an individual sibship; $(c)$ the occurrence of multiple primary adenocarcinomas of the colon; $(d)$ the occurrence of multiple primary cancers of diverse histological types; $(e)$ the appearance of adenocarcinoma of the colon in the 3rd or 4th decades of life. The pedigrees of these 5 families ( $P$, $\mathrm{M}, \mathrm{C}, \mathrm{J}$, and $\mathrm{V}$ ) are shown in Figs. 2-6, with an explanatory key in Fig. 1.

Two families with familial colonic polyposis comprising four affected and six unaffected individuals were similarly studied. The pedigree of one of these families $(F)$ is depicted in Fig. 7. In addition, three other unrelated individuals with familial polyposis were studied. Two individuals with Gardner's syndrome, a mother and daughter, were also included. The mother demonstrated a mandibular

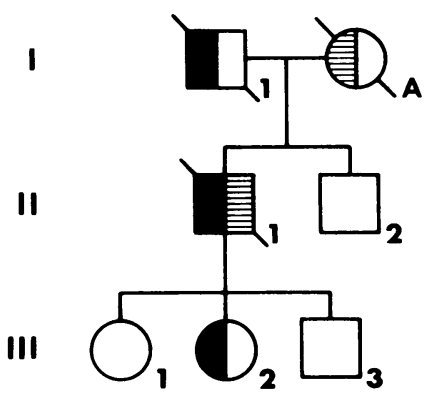

Figure 2 Colon carcinoma family $P$.

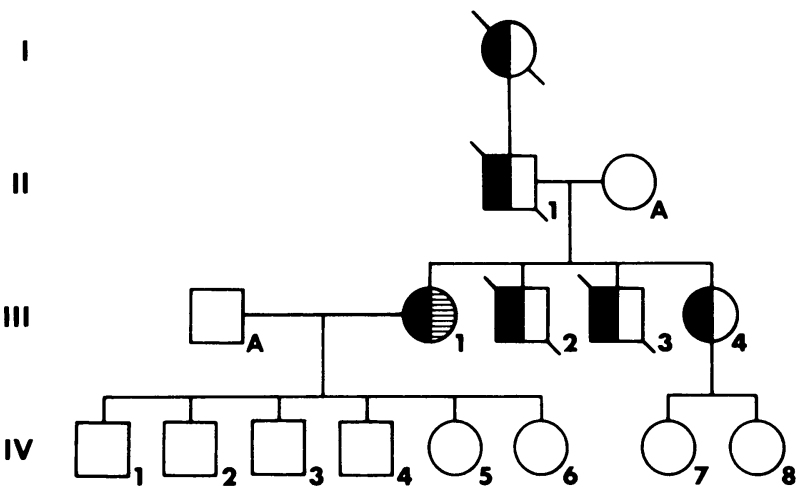

Figure 3 Colon carcinoma family $\mathrm{M}$.

osteoma, a lipoma of the thorax, and a colon carcinoma 24 yr before testing. The daughter exhibited recurrent desmoid tumors of the thorax, axilla, and abdominal wall for a period of $13 \mathrm{yr}$ before testing.

Isolation of cells. Mononuclear cells from fresh heparinized blood were isolated by Ficoll-Hypaque flotation. As described below, an aliquot of these cells was filtered through columns of Sephadex G-10 beads to remove selectively adherent mononuclear phagocytes without disturbing the relative proportions of T and B lymphocytes (20). Mononuclear cells were washed three times in calcium- and magnesium-free Hanks' balanced salt solution and were adjusted to a concentration of $1.0 \times 10^{6} \mathrm{cells} / \mathrm{ml}$ in a final culture medium of RPMI-1640 supplemented with $20 \%$ pooled normal human serum ( 77 donors), HEPES buffer $(25 \mathrm{mM})$, penicillin $(100 \mathrm{U} / \mathrm{ml})$, streptomycin $(100 \mu \mathrm{g} / \mathrm{ml})$, and fresh glutamine $(2 \mathrm{mM})$. Cell counting was performed with a hemacytometer employing $0.1 \%$ crystal violet in $10 \%$ acetic acid. This stain provides excellent definition of nuclear and cytoplasmic characteristics. Only those cells with a small round nucleus and a relative paucity of cytoplasm were included in the cell counts. Cells isolated in this manner are referred to as FH cells.

G-10 column filtration. The method of Ly and Mishell (24) was employed with modifications. An aliquot of the FH cells was suspended, after washing, at a concentration of $5-10 \times 10^{6}$ cells $/ \mathrm{ml}$ in RPMI-1640 supplemented with $20 \%$ fetal calf serum which had been previously screened for lack of cytotoxic effects. Columns of Sephadex

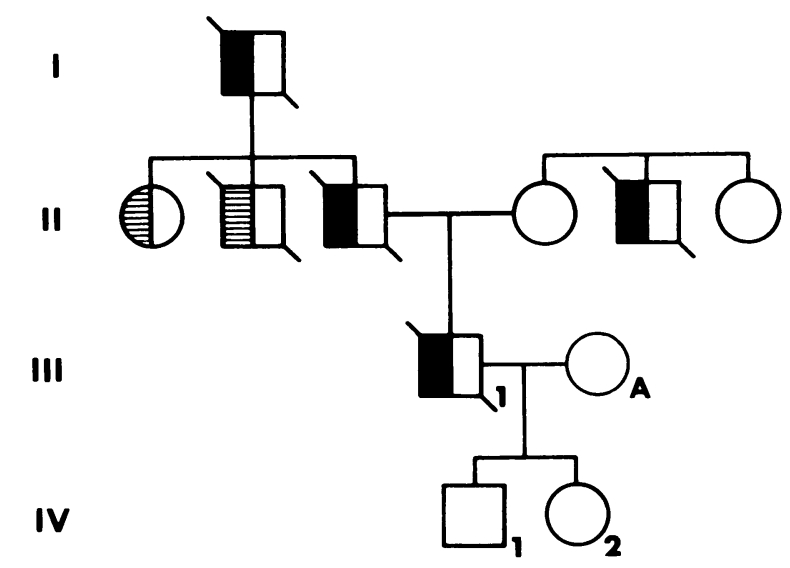

FIGURE 4 Colon carcinoma family C. 
G-10 beads were prepared as follows. A 10-ml glass syringe barrel, into which had been placed a plug of nylon wool large enough only to prevent leakage of the beads, was sterilized by autoclaving. After cooling, a bed volume of 6 $\mathrm{ml}$ of G-10 beads was placed in the upright syringe barrel. The G-10 beads had been previously allowed to swell overnight in sterile deionized water and were then boiled for $4 \mathrm{~h}$ for sterilization. The G-10 beads were stored in calcium- and magnesium-free phosphate buffered saline before their placement in the column. After the column was poured, the beads were washed with $30 \mathrm{ml}$ of RPMI-1640 with $20 \%$ fetal calf serum. The syringe was then plugged at its outlet to prevent any further elution. The aliquot of FH cells was applied to the top of the column in a volume of $2.5 \mathrm{ml}$ without allowing the cells to run into the bed. The column was placed in an incubator at $37^{\circ} \mathrm{C}$ for approximately $1 \mathrm{~h}$ to equilibrate. The column was then removed from the incubator and a slurry effected by stirring all but the bottom $1 \mathrm{ml}$ of the beads with a serological pipette. In this manner, the beads were allowed to settle through the aliquot of $\mathrm{FH}$ cells. This procedure was repeated three times, every $10 \mathrm{~min}$, with the column being placed in the incubator as the beads settled. Finally, the nonadhering cells were eluted from the column with $13 \mathrm{ml}$ of warm RPMI-1640 containing $20 \%$ fetal calf serum. The collected cells were washed three times in calciumand magnesium-free Hanks' balanced salt solution and adjusted to a concentration of $1.0 \times 10^{6}$ cells $/ \mathrm{ml}$ in the previously described final culture medium. These cells are referred to as G-10 cells.

MLC testing. By using well-defined methods (25), 5 $\times 10^{4}$ responding cells and $5 \times 10^{4} \mathrm{X}$-irradiated $(1,200 \mathrm{R})$ stimulating cells were planted in round bottom microtrays that had been commercially treated for tissue culture (Cooke model 1-221-24-1; Cooke Laboratory Products Div., Alexandria, Va.). The total reaction volume was adjusted to $150 \mu \mathrm{l}$. The cultures were incubated in a humidified atmosphere of $5 \% \quad \mathrm{CO}_{2}$ for $136 \mathrm{~h}$. During the last $16 \mathrm{~h}$ of incubation, the cultures were labeled with $2.0 \mu \mathrm{Ci}$ of tritiated thymidine. The cultures were harvested onto glass fiber filters, and the incorporation of isotope was determined by liquid scintillation spectroscopy. The incorporation of thymidine was expressed as the mean cpm of triplicate allogeneic cultures minus the mean cpm of the isogeneic control. In all experiments only fresh cells were used.

Calculation of relative response. The expression of an MLC response as a relative response (RR) is a choice

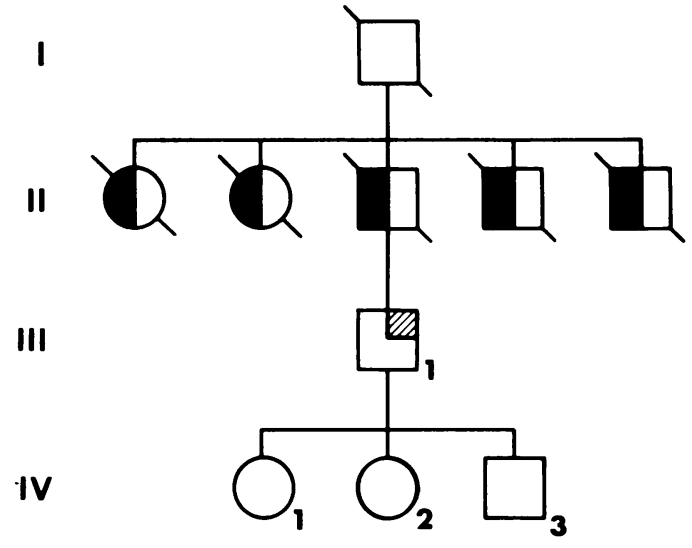

Figure 5 Colon carcinoma family J.

method because it appears subject to the least day-to-day variation as exemplified by its small variation coefficient (26). Further work involving the identification of human lymphocyte-activating determinants has emphasized the stability of expressing MLC results as RRs rather than as stimulation ratios (27).

The patient's lymphocytes were allowed to respond separately to a panel of four allogeneic stimuli, and the mean response was calculated. Concurrently, four normal individuals' lymphocytes were allowed to react with the same panel, and the mean of all the normal responses to this identical panel was calculated. This latter mean response is termed the reference value (rv). The mean of the patient's responses was then expressed as a percentage of rv and is termed the relative response (RR). For all individuals tested in this study, the responses of their $\mathrm{FH}$ cells and of their G-10 cells were determined in MLC. RR refers to the relative response of $F H$ cells, and $R R_{f}$ refers to the relative response of G-10 filtered cells.

In the various experiments, no deliberate effort was made to include the same normal individuals in the panels of responders for the generation of an rv. However, all normal individuals included were unrelated and had been previously human leukocyte antigen typed and tested in MLC to verify that a given normal panel included only combinations of individuals who were mutually strongly reactive in MLC. Satisfactory and reproducible RRs do not seem to depend on identity of normal panels from day to day but

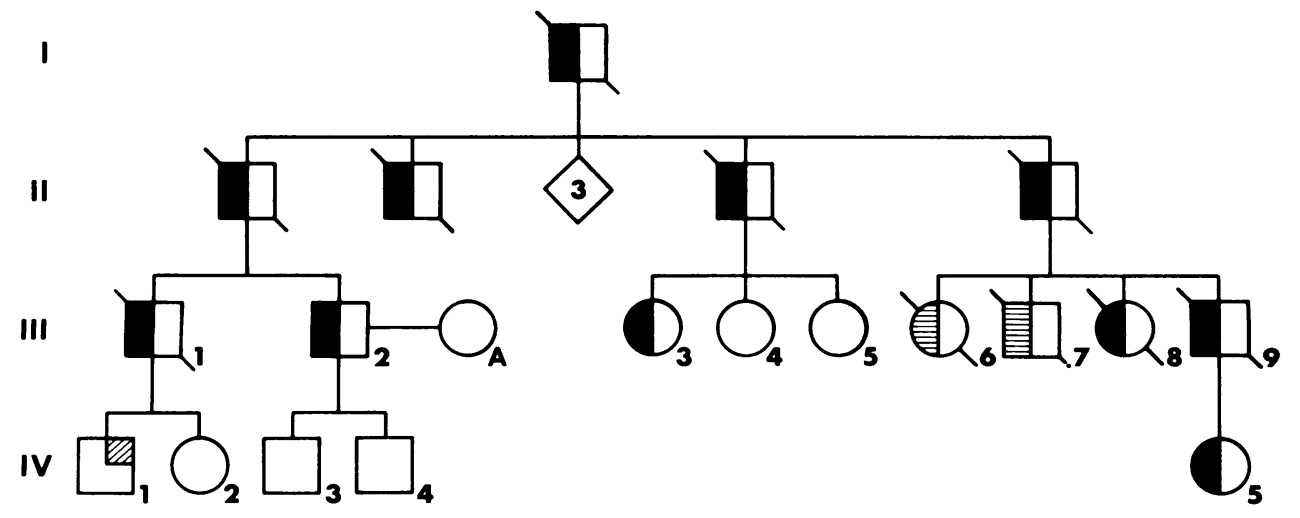

FIGURE 6 Colon carcinoma family V. 


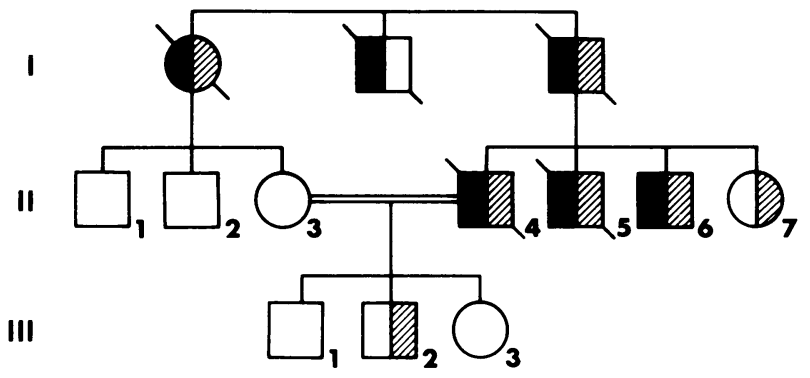

FIgURE 7 Familial polyposis family F.

rather on the generation of rather constant rv's (26). As can be seen from the tabular presentation of the results, this constancy had been quite well achieved in this study. The idea of using frozen stimulating cells, either pooled or individually, did not seem suitable for this study although such an approach could have had the potential advantage of providing some sort of constancy to the allogeneic stimuli in the various experiments. Although cryogenically preserved cells do not seem grossly inferior to fresh cells as stimulators, stimulating cells are not merely the passive carriers of antigens but provide cellular factors that assist lymphocyte responsiveness. Inasmuch as in our MLCs employing G-10 responding cells the macrophages of the stimulating cells mediate the reaction, frozen stimulating cells were avoided because the combined effects of cryogenic preservation and $\mathrm{X}$-irradiation on macrophage function in MLC at present are unknown.

Other studies of immunologic function. Lymphocyte transformation assays to phytohemagglutinin, Concanavalin A, pokeweed mitogen, and to antigens from Candida albicans, Streptococcus aureus, and Escherichia coli, in addition to quantitations of IgG, IgA, and IgM, were performed in the Clinical Immunology Parameters Laboratory of the Memorial Sloan-Kettering Cancer Center by Dr. J. Hansen and Dr. B. Dupont according to published methods (28). Dr. F. P. Siegal kindly enumerated T- and Blymphocyte populations by using well established markers $(29,30)$.

\section{RESULTS}

Normal cell-mediated immune capacity in MLC. A total of 51 unrelated normal individuals (31 males and 20 females) with an age range of 19-48 were tested in MLC as described. Family histories of each disclosed no evidence of a familial diathesis for malignancy. The RRs of these individuals showed a range of $68-150 \%$, with a geometric mean RR of $101 \%$ and an identical median RR of $101 \%$. An RR less than $2 \mathrm{SD}$ below this mean, namely, less than $68 \%$, was considered to be indicative of abnormally decreased MLC responsiveness because the RRs of the normal individuals fit a log-normal distribution. All computations involved logarithmic transformations, mandated by the fact that relative values were generated.

$M L C$ responsiveness of affected members of colon carcinoma aggregates. Table I shows the results of MLC testing of the five family aggregate members who developed colon carcinoma. Three of these in- dividuals demonstrated significantly decreased MLC responsiveness which could be restored to normal in two cases by prior removal of mononuclear phagocytes from the MLC by passage of their $\mathrm{FH}$ cells through columns of G-10 beads.

$M L C$ responsiveness of unaffected members of colon carcinoma aggregates. Table II lists the MLC responses of 18 unaffected blood relatives of the affected family members listed in Table I. 8 of these 18 individuals (44\%) showed significantly decreased cellmediated immune capacities as measured by the MLC responsiveness of their $\mathrm{FH}$ cells. Interestingly, seven of these eight abnormal individuals could demonstrate normal responses when their G-10 cells were

TABLE I

MLC Responsiveness of Affected Members of Colon Carcinoma Aggregates

\begin{tabular}{|c|c|c|c|c|c|c|c|}
\hline Family & Pedigree & Age/ & & $\mathrm{RR}$ & $\mathrm{RR}_{\mathrm{f}}$ & $\mathrm{r}$ & History \\
\hline \multirow[b]{2}{*}{$P$} & & & & $\%$ & $\%$ & $c p m$ & \\
\hline & III-2 & 27 & $\mathrm{~F}$ & 64 & 125 & 59,969 & $\begin{array}{l}\text { Ader ocarcinoma of } \\
\text { colon in } 1974 \text { at } \\
\text { age } 25 \\
\text { NED* when } \\
\text { tested }\end{array}$ \\
\hline \multirow[t]{2}{*}{$\mathbf{M}$} & III-1 & 45 & F & 58 & 50 & 54,836 & $\begin{array}{l}\text { Medullary breast } \\
\text { carcinoma in } \\
\text { June } 1975 \text { at age } \\
45\end{array}$ \\
\hline & & & & & & & $\begin{array}{l}\text { Two separate pri- } \\
\text { mary adenocarci- } \\
\text { nomas of colon } \\
\text { discovered July } \\
1975 \\
\text { NED* when tested }\end{array}$ \\
\hline $\mathbf{M}$ & III-4 & 35 & $\mathrm{~F}$ & 94 & & 47,045 & $\begin{array}{l}\text { Adenocarcinoma of } \\
\text { colon in } 1960 \text { at } \\
\text { age } 21 \\
\text { Three separate } \\
\text { primary adeno- } \\
\text { carcinomas of } \\
\text { colon discovered } \\
\text { in } 1975 \text { at age } 36 \\
\text { NED* when tested }\end{array}$ \\
\hline $\mathrm{C}$ & III-1 & 43 & $\mathbf{M}$ & 59 & 152 & 62,665 & $\begin{array}{l}\text { Adenocarcinoma of } \\
\text { colon in } 1974 \text { at } \\
\text { age } 41 \\
\text { Metastases to liver } \\
\text { when tested }\end{array}$ \\
\hline V & III-2 & 55 & $\mathbf{M}$ & 94 & & 67,045 & $\begin{array}{l}\text { Adenocarcinoma of } \\
\text { colon in } 1968 \text { at } \\
\text { age } 48 \\
\text { NED* when tested }\end{array}$ \\
\hline
\end{tabular}

* No evidence of disease. 
used. Three individuals (P-III-1, P-III-3, and V-IV-4) were available for repeat testing 16 mo after the original determinations. Employing a panel of four allogeneic stimuli different from those used originally, essentially similar results were obtained. The inability to restore normal MLC responsiveness in one individual does not necessarily imply an underlying lymphocyte abnormality. Although G-10 column filtration of mononuclear cells is a highly reliable method of removing adherent cells, a certain amount of variability has been encountered, and it is possible in this case that the filtration procedure was not optimal.

Two spouses of the affected immunologically abnormal patients whose unaffected offspring likewise showed an immunologic abnormality were available for testing (Table II). Both spouses demonstrated normal MLC responsiveness.

All unaffected individuals had undergone a thorough physical examination, including colonic endoscopy and/or barium enema, at or near the time of testing and were all judged to be free of clinically detectable malignancies or other significant disease.

$M L C$ responsiveness in familial colonic polyposis syndromes. Table III lists seven individuals with classic familial polyposis as determined by colonic endoscopy and six related individuals who were free of this finding. Although an exhaustive clinical search in each patient was made, no extracolonic manifestations which would suggest a different polyposis syndrome were found. None of these affected or unaffected individuals demonstrated deficient MLC responses. The two individuals of family $G$ with the classic colonic and extracolonic manifestations of Gardner's syndrome showed decreased MLC responsiveness. The daughter demonstrated the capacity for a normal response when her G-10 cells were tested.

Repeat studies with panels of stimulating cells different than those used for the original determinations were carried out for individuals F-II-6, F-III-1, F-III-2, F-III-3, M proband, and E proband. All RRs were again normal.

Characteristics of normal $R R_{f}$. In comparing the $R R$ and $R R_{f}$ for each of 24 normal test subjects, we have determined that these two values are seldom identical for a single individual. A more expansive analysis of this phenomenon has disclosed that the adherent cell can exert a bidirectional modulatory role in certain normal allogeneic combinations. In such cases, which are only infrequently encountered among unrelated individuals, depletion of adherent cells from the responding cell population may lead to significantly increased or decreased MLC reactivity (manuscript in preparation). In our experience, when marked changes occur they occur in no more
TABLE II

MLC Responsiveness of Unaffected Members of Colon Carcinoma Aggregates

\begin{tabular}{|c|c|c|c|c|c|c|c|}
\hline Family & Pedigree & Age/ & Sex & $\begin{array}{l}\text { Relationship to } \\
\text { affected member }\end{array}$ & RR & $\mathrm{RR}_{\mathrm{f}}$ & $\mathrm{rv}$ \\
\hline & & & & & $\%$ & $\%$ & $c p m$ \\
\hline $\mathrm{P}$ & III-1 & 25 & $\mathrm{~F}$ & Sister & 38 & 88 & 59,969 \\
\hline$P$ & III-3 & 22 & $\mathbf{M}$ & Brother & 48 & 77 & 59,969 \\
\hline $\mathbf{M}$ & IV-1 & 18 & $\mathbf{M}$ & Son & 36 & 70 & 54,836 \\
\hline M & IV-2 & 16 & $\mathbf{M}$ & Son & 66 & 78 & 54,836 \\
\hline $\mathbf{M}$ & IV-3 & 8 & $\mathbf{M}$ & Son & 53 & 60 & 54,836 \\
\hline $\mathbf{M}$ & IV-4 & 21 & $\mathbf{M}$ & Son & 105 & & 61,159 \\
\hline M & IV-5 & 13 & $\mathrm{~F}$ & Daughter & 83 & & 54,836 \\
\hline $\mathbf{M}$ & IV-6 & 19 & $\mathrm{~F}$ & Daughter & 69 & & 61,159 \\
\hline M & III-A & 46 & $\mathbf{M}$ & Spouse of III-1 & 91 & & 61,159 \\
\hline $\mathbf{M}$ & IV -7 & 5 & $\mathrm{~F}$ & Daughter & 87 & & 47,045 \\
\hline $\mathbf{M}$ & IV-8 & 4 & $\mathrm{~F}$ & Daughter & 105 & & 47,045 \\
\hline $\mathrm{C}$ & IV-I & 14 & $\mathbf{M}$ & Son & 69 & & 62,665 \\
\hline $\mathrm{C}$ & IV-2 & 15 & $\mathrm{~F}$ & Daughter & 63 & 68 & 62,665 \\
\hline $\mathrm{C}$ & III-A & 38 & $\mathrm{~F}$ & Spouse of III-1 & 86 & & 62,665 \\
\hline $\mathbf{J}$ & III-1 & 60 & $\mathbf{M}$ & Son & 139 & & 58,687 \\
\hline $\mathrm{J}$ & IV-1 & 27 & $F$ & Granddaughter & 61 & 75 & 58,687 \\
\hline V & IV-1 & 19 & $\mathbf{M}$ & Son & 39 & 71 & 53,760 \\
\hline V & IV-2 & 23 & $\mathrm{~F}$ & Daughter & 76 & & 66,462 \\
\hline V & IV-3 & 18 & $\mathbf{M}$ & Son & 93 & & 67,045 \\
\hline $\mathrm{V}$ & IV-4 & 22 & $\mathbf{M}$ & Son & 97 & & 67,045 \\
\hline
\end{tabular}

than one of the four allogeneic combinations within a panel. This variability can result in nonidentity of the $R R$ and $R_{\mathrm{f}}$ for normal subjects. Because RRs are geometric rather than arithmetic expressions, the logarithmic analysis of the variability of $R_{f} S$ in relation to $R R s$ is instructive. In our experience with normal individuals, the mean log change in the $R_{\mathrm{f}}$ from the $R R$ is 0.072 . This value represents $<1 \mathrm{SD}(0.085)$ calculated for the sample of 51 normal individuals included in this study. The mean log increase in the $R_{f} s$ for the eight immunologically abnormal individuals in the family aggregates of colon carcinoma is 0.272 , a value greater than $3 \mathrm{SD}$. Thus the ability to increase MLC responsiveness for these latter individuals by G-10 column filtration is significantly greater than the variability encountered with normal individuals.

In our previous study of patients with established malignancies (20), all patients demonstrated markedly increased MLC responsiveness to each of the four allogeneic stimuli when their G-10 cells were used as the responding population. In the present study, for all unaffected individuals whose MLC responses were considered deficient, adherent cell depletion likewise resulted in increased responsiveness in at least three and usually in all four allogeneic combinations, indicating a generalized hyporesponsiveness to allogeneic stimuli similar to that observed in patients 
TABLE III

MLC Responsiveness in Familial Colonic Polyposis Syndromes

\begin{tabular}{|c|c|c|c|c|c|c|c|}
\hline Family & $\begin{array}{l}\text { Pedigree or } \\
\text { relationship to } \\
\text { proband }\end{array}$ & Age/ & Sex & Diagnosis & $\mathbf{R R}$ & $\mathbf{R R}_{\mathbf{f}}$ & rv \\
\hline & & & & & & & \\
\hline $\mathbf{F}$ & II-3 & 44 & $\mathbf{F}$ & Normal & 95 & & 60,236 \\
\hline $\mathbf{F}$ & II-6 & 37 & $\mathbf{M}$ & $\begin{array}{l}\text { Familial polyposis } \\
\text { with some } \\
\text { malignant cells } \\
\text { detected in } \\
\text { colectomy speci- } \\
\text { men }\end{array}$ & 71 & & 60,236 \\
\hline $\mathbf{F}$ & II-7 & 32 & $\mathbf{F}$ & Familial polyposis & 90 & & 62,285 \\
\hline $\mathbf{F}$ & III-1 & 17 & $\mathbf{M}$ & Normal & 80 & & 60,236 \\
\hline $\mathrm{F}$ & III-2 & 20 & $\mathbf{M}$ & Familial polyposis & 95 & & 62,285 \\
\hline $\mathbf{F}$ & III-3 & 15 & $\mathbf{F}$ & Normal & 73 & & 62,285 \\
\hline S & Proband & 56 & $\mathbf{F}$ & Familial polyposis & 137 & & 57,401 \\
\hline $\mathrm{S}$ & Son & 32 & $\mathbf{M}$ & Normal & 79 & & 57,401 \\
\hline$S$ & Grandson & 9 & $\mathbf{M}$ & Normal & 100 & & 57,401 \\
\hline S & Granddaughter & 11 & $\mathbf{F}$ & Rectal polyp & 85 & & 57,401 \\
\hline $\mathbf{M}$ & Proband & 28 & $\mathbf{M}$ & Familial polyposis & 124 & & 68,128 \\
\hline $\mathbf{H}$ & Proband & 52 & $\mathbf{F}$ & $\begin{array}{l}\text { Familial polyposis } \\
\text { and prior adeno- } \\
\text { carcinoma of colon }\end{array}$ & 149 & & 57,713 \\
\hline $\mathrm{E}$ & Proband & 17 & $\mathbf{M}$ & Familial polyposis & 87 & & 63,895 \\
\hline G & Proband & 62 & $\mathbf{F}$ & $\begin{array}{l}\text { Gardner's syndrome } \\
\text { with prior adeno- } \\
\text { carcinoma of colon }\end{array}$ & 52 & 50 & 59,080 \\
\hline G & Daughter & 27 & $\mathbf{F}$ & Gardner's syndrome & 62 & 73 & 59,080 \\
\hline
\end{tabular}

with established cancer. Table IV gives representative examples of experiments involving unaffected family members in this study. G-10 cells from individuals P-III-1 and P-III-3 show, respectively, markedly and moderately increased responses to the panel of allogeneic stimuli as compared to the companion routine MLCs involving FH cells. Individuals M-IV-8, V-IV-4, and M-IV-4 each showed normal RRs when their FH cells were used. Using G-10 cells, it is apparent that the $R_{\mathrm{f}}$ may be greater than, less than, or nearly identical to the RR. For all unaffected individuals in this study whose MLC responses were considered normal, their $\mathbf{R R}_{f} s$ may have diverged from the respective RRs, but this divergence was of a magnitude similar to the variability observed with a normal nonpatient sample.

Other immune parameters. Other parameters of cellular and humoral immunity were studied in the majority of these individuals who demonstrated deficient MLC responses. No numerical deficiencies of circulating $\mathrm{T}$ lymphocytes were detected. The ability of peripheral blood lymphocytes to respond to nonspecific mitogens and to common antigens was normal in all patients with the exception of one individual with Gardner's syndrome (G-daughter) who showed a moderately depressed phytohemagglutinin response. Quantitative radial immunodiffusion revealed serum levels of IgG, IgA, and IgM in all individuals to be normal for their respective age and sex. Secretory IgA was not quantitated.

\section{DISCUSSION}

The MLC was specifically chosen as the in vitro test of cellular immunity that would be most meaningful in this context. Lymphocyte reactivity in MLC represents the response to foreign histocompatibility antigens, antigens which are only subtly different from those of the responding cell. As such, it represents the recognition phase of the in vivo allograft response (31) and thus becomes a model which may well be relevant for the tumor situation. In addition, the MLC requires the participation and interaction of both lymphocyte and mononuclear phagocyte (or, 
loosely, macrophage), an identical situation which obtains with in vivo cellular immune reactions. Responses in MLC reactions after depletion of both stimulating and responding cell populations of macrophages are severely attenuated (32), although the presence of macrophages from either the stimulating or responding cells seems sufficient for the mediation of the MLC. Thus, the MLC can become a test of both lymphocyte and macrophage function in the response to foreign tissue.

That three of five patients with recent or concurrent carcinoma showed deficient recognitive immunity is not surprising. Patients with established lung cancer (33) or with established head and neck squamous cell carcinoma (34) frequently show impaired lymphocyte blastogenic abilities to allogeneic cells. In addition, $29 \%$ of head and neck squamous cell carcinoma patients studied in one series continued to manifest impaired cutaneous reactivity or anergy to dinitrochlorobenzene despite the fact they had remained free of disease for as long as $14 \mathrm{yr}$ (35).

Provocative, however, is the finding that, in family aggregates of colon carcinoma, 8 of 18 cancer-free individuals showed the same deficit of recognitive immunity as did their affected relatives. In this study, three individuals (P-III-1, M-IV-1, and V-IV-1) showed RRs $>5$ SD below the mean of normal responsiveness, and two individuals (P-III-3 and M-IV-3) showed RRs $>3$ SD below the mean. The remaining three immunologically abnormal individuals (M-IV-2, C-IV-2, and J-IV-1) showed less pronounced but significantly decreased ( $>2$ SD) MLC responsiveness. Accepting the statistically derived RR of $<68 \%$ as being abnormal, one would generally expect to find an individual with normal recognitive immunity but with an $\mathrm{RR}$ of $<68 \%$ in only 1 of every 44 "normal" individuals tested. Although this patient sample is limited in size, it nevertheless seems to represent suggestive evidence that deficiencies of recognitive immunity appear to aggregate in families in which colon carcinoma aggregates.

An attempt to understand the nature of this in vitro demonstration of impaired cellular immunity took the form of studying the responses of patient lymphocytes that had been depleted of adherent cells by passage of the mononuclear cells through columns of G-10 beads. Recent work has shown that functional adherent cell abnormalities may preclude optimal mediation of the MLC. Mononuclear cells from patients with herpes zoster infections demonstrate an apparent functional macrophage deficit rendering

TABLE IV

Responses in Routine MLC Compared to Responses with Filtered Cells

\begin{tabular}{|c|c|c|c|c|c|c|}
\hline \multicolumn{2}{|c|}{$\begin{array}{l}\text { Responding cells } \\
\text { of individual }\end{array}$} & \multirow[b]{2}{*}{$\mathbf{R R}$} & \multirow[b]{2}{*}{$\mathbf{R R}_{\mathrm{f}}$} & \multirow{2}{*}{$\begin{array}{l}\text { FH responding } \\
\quad \text { cells, } 4 \\
\text { allogeneic stimuli }\end{array}$} & \multirow{2}{*}{$\begin{array}{l}\text { G-10 responding } \\
\text { cells, same } \\
\text { allogeneic stimuli }\end{array}$} & \multirow{2}{*}{$\begin{array}{l}\text { Change in MLC } \\
\text { responsiveness }\end{array}$} \\
\hline Family & Pedigree & & & & & \\
\hline & & $\%$ & $\%$ & & & $\%$ \\
\hline $\mathbf{P}$ & III-1 & 38 & 88 & $\begin{array}{l}35,548 \pm 200 * \\
13,113 \pm 123 \\
25,993 \pm 3,441 \\
17,647 \pm 1,583\end{array}$ & $\begin{array}{l}54,163 \pm 1,988 \\
57,074 \pm 1,752 \\
63,736 \pm 3,121 \\
35,314 \pm 2,491\end{array}$ & $\begin{array}{r}+52 \\
+335 \\
+145 \\
+100\end{array}$ \\
\hline $\mathbf{P}$ & III-3 & 48 & 77 & $\begin{array}{l}33,636 \pm 3,140 \\
15,229 \pm 1,974 \\
52,480 \pm 4,166 \\
14,582 \pm 520\end{array}$ & $\begin{array}{l}55,936 \pm 3,199 \\
49,113 \pm 3,715 \\
48,217 \pm 4,583 \\
31,133 \pm 2,688\end{array}$ & $\begin{array}{r}+66 \\
+222 \\
-8 \\
+114\end{array}$ \\
\hline $\mathbf{M}$ & IV-8 & 105 & 92 & $\begin{array}{l}58,875 \pm 3,075 \\
61,735 \pm 923 \\
47,986 \pm 4,106 \\
29,543 \pm 1,872\end{array}$ & $\begin{array}{l}47,230 \pm 3,102 \\
56,053 \pm 3,586 \\
42,046 \pm 2,788 \\
28,620 \pm 1,204\end{array}$ & $\begin{array}{r}-20 \\
-9 \\
-12 \\
-3\end{array}$ \\
\hline V & IV-4 & 97 & 96 & $\begin{array}{l}55,993 \pm 2,666 \\
62,487 \pm 2,397 \\
64,148 \pm 882 \\
77,335 \pm 3,868\end{array}$ & $\begin{array}{l}60,963 \pm 2,750 \\
64,177 \pm 3,552 \\
64,180 \pm 3,536 \\
68,485 \pm 4,068\end{array}$ & $\begin{array}{r}+9 \\
+3 \\
0 \\
-11\end{array}$ \\
\hline $\mathbf{M}$ & IV-4 & 105 & 119 & $\begin{array}{l}64,591 \pm 4,539 \\
56,470 \pm 2,982 \\
70,761 \pm 990 \\
65,109 \pm 1,744\end{array}$ & $\begin{array}{l}64,504 \pm 2,750 \\
66,889 \pm 317 \\
72,876 \pm 2,586 \\
86,198 \pm 1,914\end{array}$ & $\begin{array}{r}0 \\
+18 \\
+3 \\
+32\end{array}$ \\
\hline
\end{tabular}

* Results are expressed as the mean cpm of triplicate allogeneic cultures minus the mean cpm of triplicate isogeneic cultures \pm 1 SEM. 
these macrophages unable to mediate the MLC (36). Relevant for the cancer situation is our recent work (20) which demonstrated that mononuclear cells from cancer patients that showed significantly decreased MLC responses could often show normal responses if the adherent cells of the cancer patient were eliminated from the MLC. This report suggested a perturbation of macrophage function in the patient with established cancer whereby the macrophage could paradoxically suppress a potentially normal lymphocyte response to an allogeneic stimulus.

Similarly in this study, of the three family aggregate patients with recent or concurrent cancer who showed abnormally low MLC responses, two were able to manifest normal responses when their adherent cells were eliminated from the culture. Most provocatively, of the eight unaffected blood relatives whose mononuclear cells showed deficient MLC responses, seven could be restored to normal and one to near normal by adherent cell elimination.

That the defect of recognitive immunity which clusters in these family aggregates of colon carcinoma appears to be a similar perturbation of macrophage function during the response to an allogeneic stimulus is a tentative conclusion which should be entertained with a certain degree of conservatism. Of the individuals whose RRs were $>3$ SD below the mean of normal responsiveness, it is rather clear that adherent cell elimination usually allowed normal MLC responses to obtain. For the individuals whose RRs were significantly but not as dramatically depressed, adherent cell elimination allowed only a modest increase of MLC reactivity to normal levels. Our previously published cell marker analysis of G-10 cells revealed no changes in the relative proportions of lymphocytes which spontaneously rosette with sheep erythrocytes or which bear surface immunoglobulin detected by a polyvalent antihuman immunoglobulin antiserum while latex-ingesting cells were virtually eliminated (20). Further cell marker analyses (data not shown) have revealed no significant changes in the relative proportions of Ripley positive lymphocytes or of lymphocytes which bear surface IgM employing $\mathrm{F}\left(\mathrm{ab} \mathrm{b}^{\prime}\right)_{2}$ reagents, whereas alpha-naphthyl esterase positive cells are nearly completely eliminated. These data are consistent with the interpretation that the increased responsiveness of G-10 cells of these immunologically abnormal individuals is the result of the removal of suppressive adherent cells belonging to the monocyte-macrophage series. It should be emphasized that an unidentified population of adherent cells which are not macrophages, but which are co-retained with macrophages in columns of G-10 beads, could be responsible for the suppressive effect observed in MLC as a certain amount of lymphocyte loss is experienced with G-10 column filtration.

This group of patients, however, showed normal in vitro responses to common antigens and mitogens, responses which are also macrophage dependent (37). This is not an irreconcilable dichotomy, but is reminiscent of the immunologic profile of patients with the Wiskott-Aldrich syndrome who show deficient responses in vitro to certain antigens and to allogeneic cells but are able to manifest normal lymphocyte responsiveness to nonspecific mitogens (38). As such, our findings are discordant with those of Creagan and Fraumeni (19) who reported decreased lymphocyte blastogenesis to streptolysin-O and phytohemagglutinin in a family aggregate of gastric carcinoma.

It is interesting that none of the affected or unaffected individuals from families with familial polyposis showed any deficit of recognitive immunity, whereas the two patients with Gardner's syndrome did. These two syndromes are considered to be genetically distinct, based upon their differing phenotypic expressions (39). Although we were able to study only two individuals with Gardner's syndrome, the possibility is tenable that a deficit of recognitive immunity may be an unsuspected component of Gardner's syndrome and could ostensibly be a reflection of the greater propensity for neoplasia in this syndrome relative to polyposis coli. The expression of defective recognitive immunity may, in fact, further serve to differentiate the various familial colonic polyposis syndromes.

Such a limited study can generate no definitive conclusions regarding a possible genetic basis for this immunologic abnormality. Nevertheless, the apparent vertical mode of transmission through two generations in the families, M, C, and G is suggestive. In addition, the number of siblings showing this immunologic abnormality in sibships of families $P$ ( 3 of 3 ), M (3 of 6), C ( 1 of 2$), \mathrm{V}$ (1 of 2), and G (1 of 1 ), coupled with the finding that in two of these families the unaffected parent was immunologically normal, is not inconsistent with a dominant mode of inheritance. The possibility that this defect is secondary to some extragenetic factor is, of course, equally probable. The data generated by this study can pose the question whether a genetically transmitted immunologic determinant may be contributory to the genesis of malignancy in some of these families.

\section{ACKNOWLEDGMENTS}

This work was supported by a fellowship from the National Cancer Institute (1 F22 CA01311-01) and by the following grants and contracts from the National Institutes of Health: CA-17404, AI-11843, CA-08748, and N01 CP43366; also by the Zelda R. Weintraub Cancer Fund. 


\section{REFERENCES}

1. Taylor, W. B., D. E. Anderson, J. B. Howell, and C. S. Thurston. 1968. The nevoid basal cell carcinoma syndrome. Autopsy findings. Arch. Dermatol. 98: 612-614.

2. Knudson, A. G., Jr. 1971. Mutation and cancer: statistical study of retinoblastoma. Proc. Natl. Acad. Sci. U. S. A. 68: $820-823$.

3. Miller, R. W. 1970. Neoplasia and Down's syndrome. Ann. N. Y. Acad. Sci. 171: 637-644.

4. Swift, M. 1971. Fanconi's anemia in the genetics of neoplasia. Nature (Lond.). 230: 370-373.

5. Rauh, J. L., and S. W. Soukup. 1968. Bloom's syndrome. Am. J. Dis. Child. 116: 409-413.

6. Cleaver, J. E. 1969. Xeroderma pigmentosum: A human disease in which an initial stage of DNA repair is defective. Proc. Natl. Acad. Sci. U. S. A. 63: 428-435.

7. Kersey, J. H., B. D. Spector, and R. A. Good. 1973. Primary immunodeficiency diseases and cancer: the immunodeficiency-cancer registry. Int. J. Cancer. 12: $333-347$.

8. McConnell, R. B. 1966. Polyposis. In The Genetics of Gastro-Intestinal Disorders. Oxford University Press, London. 156-159.

9. Pierce, E. R., T. Weisbord, and V. A. McKusick. 1970. Gardner's syndrome: formal genetics and statistical analysis of a large Canadian kindred. Clin. Genet. 1: $65-80$.

10. Turcot, J., J-P., Després, and F. St. Pierre. 1959. Malignant tumors of the central nervous system associated with familial polyposis of the colon: report of two cases. Dis. Colon Rectum. 2: 465-468.

11. Savage, D. 1956. A family history of uterine and gastrointestinal cancer. Br. Med. J. 2: 341-343.

12. Peltokallio, P., and V. Peltokallio. 1966. Relationship of familial factors to carcinoma of the colon. Dis. Colon Rectum. 9: 367-370.

13. Lynch, H. T., and A. J. Krush. 1967. Heredity and adenocarcinoma of the colon. Gastroenterology. 53: 517-527.

14. Lynch, H. T., and A. J. Krush. 1971. Cancer family "G" revisited: 1895-1970. Cancer. 27: 1505-1511.

15. Lynch, H. T. 1974. Familial cancer prevalence spanning eight years: family N. Arch. Intern. Med. 134: 931938.

16. Fraumeni, J. F., Jr., C. L. Vogel, and V. T. DeVita. 1969. Familial chronic lymphocytic leukemia. Ann. Intern. Med. 71: 279-284.

17. Potolsky, A. I., C. W. Heath, Jr., C. E. Buckley, III, and D. T. Rowlands, Jr. 1971. Lymphoreticular malignancies and immunologic abnormalities in a sibship. Am. J. Med. 50: 42-48.

18. Fraumeni, J. F., Jr., W. Wertelecki, W. A. Blattner, R. D. Jensen, and B. G. Leventhal. 1975. Varied manifestations of a familial lymphoproliferative disorder. Am. J. Med. 59: 145-151.

19. Creagan, E. T., and J. F. Fraumeni, Jr. 1973. Familial gastric cancer and immunologic abnormalities. Cancer. 32: 1325-1331.

20. Berlinger, N. T., C. Lopez, and R. A. Good. 1976. Facilitation or attenuation of mixed leukocyte culture responsiveness by adherent cells. Nature (Lond.). 260: $145-146$.

21. Calderon, J., and E. R. Unanue. 1975. Two biological activities regulating cell proliferation found in cultures of peritoneal exudate cells. Nature (Lond.). 253: 359361 .

22. Nathan, C. F., and W. D. Terry. 1975. Differential stimulation of murine lymphoma growth in vitro by normal and BCG-activated macrophages. J. Exp. Med. 142: 887-902.

23. Nathan, C. F., V. M. Hill, and W. D. Terry. 1976. Isolation of a subpopulation of adherent peritoneal cells with anti-tumour activity. Nature (Lond.). 260: 146148.

24. Ly, I. A., and R. I. Mishell. 1974. Separation of mouse spleen cells by passage through columns of Sephadex G-10. J. Immunol. Methods. 5: 239-247.

25. Jørgenson, F., and L. U. Lamm. 1974. MLC-a micromodification of the mixed leukocyte culture technique. Tissue Antigens. 4: 482-494.

26. Thorsby, E., R. du Bois, and H. Bondevik. 1974. Joint report from a mixed lymphocyte culture workshop. Tissue Antigens. 4: 507-525.

27. Thorsby, E., A. Helgesen, B. Rankin, E. Möller, and A. Kaakinen. 1975. Identification of five lymphocyte activating determinants in man. Tissue Antigens. 6: $147-160$.

28. Dupont, B., and R. A. Good. 1975. Lymphocyte transformation in vitro in patients with immunodeficiency diseases: use in diagnosis, histocompatibility testing and monitoring treatment. In Immunodeficiency in Man and Animals. D. Bergsma, editor. Sinauer Associates, Inc., Sunderland, Mass. 477-485.

29. Siegal, F. P., B. Pernis, and H. G. Kunkel. 1971. Lymphocytes in human immunodeficiency states: a study of membrane-associated immunoglobulins. Eur. J. Immunol. 1: 482-486.

30. Bentwich, Z., S. D. Douglas, F. P. Siegal, and H. G. Kunkel. 1973. Human lymphocyte-sheep erythrocyte rosette formation: some characteristics of the interaction. Clin. Immunol. Immunopathol. 1: 511-522.

31. Bach, F. H. 1974. Normal histocompatibility antigens as a model for tumors. Am. J. Clin. Pathol. 62: 173183.

32. Twomey, J. J., O. Sharkey, Jr., J. A. Brown, A. H. Laughter, and P. H. Jordan, Jr. 1970. Cellular requirements for the mitotic response in allogeneic mixed leukocyte cultures. J. Immunol. 104: 845-853.

33. Han, T., and H. Takita. 1972. Impaired lymphocyte response to allogeneic cultured lymphoid cells in patients with lung cancer. N. Engl. J. Med. 286: 605606.

34. Berlinger, N. T., and R. A. Good. 1976. Concomitant immunopathology with squamous cell carcinomas of the head and neck regions. Trans. Am. Acad. Opthalmol. Oto-laryngol. 82: ORL-588-594.

35. Twomey, P. L., W. J. Catalona, and P. B. Chretien. 1974. Cellular immunity in cured cancer patients. Cancer. 33: 435-440.

36. Twomey, J. J., and O. Sharkey. 1972. An adaptation of the mixed leukocyte culture test for use in evaluating lymphocyte and macrophage function. J. Immunol. 108: $984-990$.

37. Rosentreich, D. L., and J. M. Wilton. 1975. The mechanism of action of macrophages in the activation of Tlymphocytes in vitro by antigens and mitogens. In Immune Recognition. A. S. Rosenthal, editor. Academic Press, Inc., New York. 113-132.

38. Blaese, R. M., W. Strober, and T. A. Waldmann. 1975. Immunodeficiency in the Wiskott-Aldrich syndrome. In Immunodeficiency in Man and Animals. D. Bergsma, editor. Sinauer Associates, Inc., Sunderland, Mass. 250-254.

39. McKusick, V. A. 1962. Genetic factors in intestinal polyposis. J. Am. Med. Assoc. 182: 271-277.

Defective Immunity in Cancer Families 